\title{
A coerência e a coesão nos textos de opinião de alunos do 50 ano de ensino fundamental
}

\section{The coherence and the cohesion in opinion texts by $5{ }^{\mathrm{TH}}$ year elementary education students}

\author{
Luciana Ribeiro Pinheiro \\ Universidade Federal do Paraná - UFPR, Curitiba, Paraná, Brasil

\section{Sandra Regina Kirchner Guimarães} \\ Universidade Federal do Paraná - UFPR, Curitiba, Paraná, Brasil
}

\begin{abstract}
RESUMO
Este artigo aborda a produção de textos de opinião como uma atividade facilitada pelas habilidades metacontextuais relativas à coerência e à coesão. O objetivo do estudo apresentado foi identificar e descrever o uso de operadores organizacionais de coesão e a coerência em textos de opinião de 18 alunos do 5 o ano do ensino fundamental de uma escola pública. Foi realizada uma intervenção (sequência didática) que comportou a utilização de operadores argumentativos e organizacionais como ferramentas que aprimoram a escrita de textos de opinião. Em virtude do caráter qualitativo da pesquisa e da participação de um número reduzido de alunos as conclusões deste estudo não podem ser generalizadas. Contudo, a intervenção revelou-se eficaz tanto como instrumento de investigação quanto como instrumento de instrução pedagógica. Acredita-se que o tipo de sequência didática utilizado pode servir para contínua avaliação das aprendizagens e dificuldades reveladas pelos alunos, subsidiando (re)elaborações nos planejamentos pedagógicos voltados para a produção de textos de opinião.
\end{abstract}

Palavras-chave: Opinião, Coerência, Coesão, Ensino.

\begin{abstract}
This paper examines the production of argumentative texts as an activity facilitated by meta-contextual skills related to coherence and cohesion. The central objective of the study was to identify and describe the use of the organizational operators of cohesion and coherence in argumentative texts by 18 students in the 5th year of elementary education at a public school. An intervention was implemented (didactical sequence) and included the use and reflection regarding argumentative and organizational operators as tools to enhance the writing of argumentative texts. Because of the qualitative nature of this research and the participation of a small number of students, conclusions of this study cannot be generalized. However, the didactical sequence proved to be effective both as a research tool and as a pedagogical tool for instruction. It is believed that this type of intervention can be useful for the continuous diagnostic assessment of learning and difficulties
\end{abstract}


shown by students, subsidizing re-workings in the planning of pedagogical activities aimed at producing argumentative texts.

Keywords: Argumentative text, Coherence, Cohesion, Teaching.

\section{I ntrodução}

Nas últimas três décadas, pesquisas de diferentes áreas relacionadas à educação reforçam a ideia de que escrever um texto implica muitos processos metalinguísticos. Nesta perspectiva, vários estudos têm investigado as relações entre as habilidades metalinguísticas e o aperfeiçoamento na linguagem escrita. Contudo, as pesquisas empíricas abordando a relação entre habilidades metacontextuais e a produção de textos ainda são muito escassas. Em se tratando de textos argumentativos nos anos iniciais do ensino fundamental, essas são ainda mais raras.

Em termos teóricos, destacam-se duas principais abordagens que têm embasado as investigações sobre produção textual e metalinguagem. Tais abordagens se contrapõem tanto na concepção de como as representações mentais das estruturas textuais são construídas (e se manifestam para subsidiar as produções) quanto na concepção de como uma determinada habilidade metalinguística se envolve na produção textual.

De um lado, encontra-se a posição cognitivista que defende a importância da consciência/conhecimento de esquemas textuais para delinear o percurso da produção escrita, visto que esses esquemas funcionariam como representações cognitivas abstratas (ADAM, 1992; VAN DIJK, 1992). Tais representações mentais serviriam como modelos que precedem o texto. Questiona-se, no entanto, se modelos mentais preexistentes são suficientes para abarcar a complexidade da produção argumentativa, visto que esta ocorre sob condições de embates marcados por possibilidades de alternância de pontos de vista, os quais são estabelecidos entre o escritor e as múltiplas "vozes sociais", com as quais dialoga, conforme defende Bakhtin (2010, 1995).

Ainda com a perspectiva cognitivista, a investigação sobre os processos envolvidos na produção textual conduziu Gombert (1992) a cunhar o termo consciência metatextual para se referir a um tipo de habilidade metalinguística na qual o indivíduo toma o texto como um objeto de reflexão. As propriedades e as relações intralinguísticas estabelecidas no texto são analisadas a partir de um monitoramento deliberado. Assim, de acordo com Spinillo (2009, p. 78), o foco de atenção do indivíduo afasta-se da situação de comunicação e se centra no "texto em si mesmo: sua estrutura, suas partes constituintes, suas convenções linguísticas e marcadores (coesivos, pontuação)". A consciência metatextual abarca todas as 
especificidades intralinguísticas de produção e análise de um texto em sua inteireza, ou seja, desde as características microlinguísticas (reflexão sobre empregos de coesitivos, sobre marcas de pontuação, etc) quanto às características macrolinguísticas (reflexão sobre conteúdos explicitados no texto, sobre formas linguísticas e elementos característicos do tipo/gênero textual).

Por outro lado, há autores que se divergem da posição cognitivista de considerar as estruturas textuais como modelos cognitivos preexistentes e de considerar viável analisar deliberadamente a produção textual dissociada da sua função eminentemente social e comunicativa. Bronckart, por exemplo, considera que os protótipos textuais são "constructos teóricos elaborados secundariamente a partir do exame das sequências empiricamente observáveis nos textos". Os protótipos "procedem da experiência do intertexto, em suas dimensões práticas e históricas e podem, portanto, como todas as propriedades desse intertexto, modificar-se permanentemente" (BRONCKART, 1999, p. 233).

Nesta perspectiva, a linguagem é concebida como uma atividade social que não ocorre a priori. Portanto, as atividades que envolvem o texto como unidade de análise e reflexão deliberadas não podem destituí-lo da situação de comunicação a qual ele se destina. A concepção de consciência de habilidades que viabilizam a análise, a reflexão e a manipulação do uso e, portanto, dos atributos da língua deve levar em consideração principalmente a sua função social/comunicativa, como defendem Bronckart (1999) e Vygotsky (1996; 1991), e parâmetros de situação dialógica em que o texto é produzido (Leitão, 2003; 2007).

Diante da complexidade do tema optou-se por trabalhar um quadro referencial composto por perspectivas epistemológicas de linguagem que visam explicar o fenômeno linguístico como uma atividade social (BRONCKART, 1999; DOLZ; NOVERRAZ; SCHNEUWLY, 2004) e dialógica (BAKHTIN, 2010; LEITÃO, 2003, 2000).

\subsection{0 texto de opinião: um texto argumentativo}

Com frequência, a atividade discursiva no contexto escolar se limita a compreensão e produção de textos narrativos e descritivos. Considera-se que a escrita argumentativa é complexa demais para as crianças, deixando-se de lado importantes manifestações de comunicação realizadas por elas, nas quais são utilizadas diferentes modalidades de organização discursiva. Leitão (2001) afirma que a competência de um sujeito na escrita argumentativa não surge automaticamente como consequência da aquisição de capacidades gerais de escrita e de argumentação. Segundo a autora, a escrita argumentativa exige habilidades e conhecimentos somente adquiridos por meio de aprendizagens específicas. Porém, o planejamento 
educacional voltado para a sistematização destes conhecimentos e habilidades aparece muito tarde no processo de escolarização, normalmente nos cursos e séries pré-vestibulares. No entanto, "acredita-se que, já em fases iniciais da escolarização, é possível intervir pedagogicamente de um modo que favoreça a formação de bons produtores de textos argumentativos" (LEITÃO, 2001a, p. 119). Sumariando, de acordo com o aporte teórico revisado em vários autores (BAKHTIN, 2010; BRONCKART, 1999; DOLZ; NOVERRAZ; SCHNEUWLY, 2004) pode-se dizer que o texto deve ser estudado por ser um objeto significante ou de significação, que se constitui dialogicamente, abarcando dimensões do contexto histórico, social e cultural. Como consequência, o homem revela-se a partir das suas produções textuais, sendo que os contextos de interação são a fonte de origem e de desenvolvimento da linguagem. As múltiplas vozes que se inter-relacionam de diferentes maneiras, as situações de interações sociais e o contexto histórico-social devem ser considerados nos processos relativos à produção do texto.

Segundo os mesmos autores citados anteriormente, o empreendimento do homem na produção de texto viabiliza (re)significações de mundo, pois, todos os campos da atividade humana estão ligados ao uso da linguagem. Assim, tanto as suas características quanto as suas formas, são tão diversificadas quanto os campos de atuação existentes. Os textos, portanto, exprimem as circunstâncias específicas e as intenções de cada referido campo, não apenas por seu conteúdo temático e pelo estilo de linguagem, mas, principalmente, por sua construção composicional. Dessa forma, os diferentes campos de atuação social originam diferentes gêneros, que são relativamente estáveis (BAKHTIN, 2010). O conjunto de gêneros textuais constitui uma listagem aberta e passível de ampliação e variações a depender das necessidades impostas pelos contextos de interação (MARCUSCHI, 2002; 2008). Assim sendo, cada gênero possui um conjunto de propriedades que os caracterizam, bem como marcas linguísticas específicas que os diferenciam.

O texto de opinião é um gênero textual que se caracteriza como argumentativo, sendo elaborado a partir de um tema polêmico capaz de suscitar a discussão e o embate de ideias. De acordo com Bränkling (2000, p. 227), "é um gênero de discurso em que se busca convencer o outro de uma determinada ideia, influenciá-lo, transformar os seus valores por meio de um processo de argumentação a favor de uma determinada posição assumida pelo produtor e de refutação de possíveis opiniões divergentes". Considera-se o texto de opinião como um texto argumentativo, pois com sugere Leitão (2000), ele demanda do escritor tanto a definição/defesa de um ponto de vista quanto antecipar/reagir a posições alternativas. $\mathrm{Na}$ concepção proposta por Leitão, os enunciados constitutivos do texto argumentativo são como um 
diálogo virtual escritor-leitor. Portanto, a produção desse tipo de texto exige que o escritor instaure adequadamente marcas linguísticas a partir de condições enunciativas específicas: o que se quer expressar? O que se pretende que seja entendido no texto? Quais são as marcas linguísticas adequadas para expressar a definição/defesa do ponto de vista? Quais são os conectivos que expressam posições alternativas?

Destaca-se que na vertente teórica, que aqui se defende, a argumentatividade é uma ação de caráter social e discursiva com vistas ao convencimento do interlocutor a partir da defesa de pontos de vista. Por isso, a escolha das marcas linguísticas em um texto argumentativo está relacionada aos valores e às ideias que se pretende estabelecer no diálogo virtual (escrita). Afinal, o dialogismo presente na produção argumentativa faz com que o processo da escrita seja concebido como um fenômeno que se constituiu a partir do contato com o outro, e é a presença desse outro que orienta o discurso, estabelecendo a voz de um destinatário no interior de um texto (BRANDÃO, 1997; AMORIM; ROSSETI-FERREIRA, 2008). Além disso, outras vozes também se manifestam no ato da escrita, configuradas no interdiscurso, ou seja, encontram-se no diálogo que todo discurso trava com discursos de outros (SANTA-CLARA; LEITÃO, 2011).

\subsection{A coesão e a coerência textuais}

No que se refere à produção escrita, salienta-se que a coerência e a coesão entrelaçam-se possibilitando a composição da textualidade. Koch (2010) e Koch e Travaglia (2007) argumentam que a coerência não depende da coesão para propiciar sentido ao texto. A coerência estabelece a textualidade por meio de uma sequência linguística que viabiliza a interação na interlocução, enquanto a coesão contribui para instituir o sentido pretendido, para facilitar o entendimento.

De acordo com Koch e Travaglia (2007), a coerência é responsável pela textualidade, ou seja, ela possibilita que uma sequência linguística, uma sequência de frases, seja percebida pelo interlocutor como um texto, como uma unidade significativa global. Na opinião desses autores, não existem textos incoerentes em si, mas pode existir incoerência no que se refere à determinada situação comunicativa. Nesses termos, um determinado texto pode apresentar-se coerente para um indivíduo e incoerente para outro.

De outra parte, os processos de coesão não são simples princípios sintáticos, eles dão conta da sequência superficial do texto constituindo os padrões formais na transmissão de conhecimentos e sentidos (MARCUSCHI, 2008, 1995). Os elementos de coesão são sinais de articulação que assinalam relações semânticas e (ou) discursivas interfrásticas. Koch (2010) explica que estes elementos 
são responsáveis pelos encadeamentos de orações, enunciados ou sequências maiores do texto. Nas palavras do autor, a coesão é "a forma como os elementos linguísticos presentes na superfície do textual se interligam, se interconectam, por meio de recursos também linguísticos, de modo a formar um 'tecido' (tessitura), uma unidade de nível superior à da frase, que dela difere qualitativamente" (KOCH, 2009, p. 35).

Nesta perspectiva, entende-se que é possível construir textos que não apresentam elementos coesivos, pois seu sentido é dado no nível contextual, no nível da coerência. Por outro lado, há textos que embora usem mecanismos de coesão como auxílio - apresentam discursos isolados, sem condições suficientes para a formação da textualidade por faltar-Ihes a coerência (MARCUSCHI, 1995; KOCH, 2010; KÖCHE; BOFF; PAVANI, 2009). Em virtude disso, Marcuschi (2008) ao tratar sobre coesão defende que a "sua presença não garante a textualidade e sua ausência não impede a textualidade" ( $p$. 104).

Em suma, a coesão e a coerência colaboram para que o corpo discursivo seja estruturado, possibilitando ao tipo textual e gênero a "substancialidade" e "materialidade" linguística.

$\mathrm{Na}$ tentativa de compreender dificuldades encontradas na produção da argumentação, variados estudos têm sido realizados (SANTACLARA; LEITÃO, 2011; BOFF; KÖCHE; MARINELLO, 2009; ROCHA, 2012; LIMA, 2006; LEITÃO 2003; 2001; 2000; LEITÃO; BANKSLEITE, 2006; PINHEIRO; LEITÃO, 2007; AZEVEDO, 2002; 2009; SOUZA, 2003; SANTOS, 2005; SANTOS; 1997; BRÄNKLING, 2000) enfatizando vários fatores: aspectos cognitivos envolvidos na produção da estrutura argumentativa; aspectos relacionados ao funcionamento da língua; aspectos envolvidos na definição/defesa de pontos de vista e no manejo de contra-argumentos.

Entre esses estudos, destaca-se o de Bränkling (2000), que realizou uma investigação com o intuito de analisar a pertinência e a aplicabilidade de um projeto de escrita de textos de opinião, orientando-se pelos pressupostos apresentados nos Parâmetros Curriculares Nacionais (PCNs) de Língua Portuguesa de 3o e 4o ciclos e articulando-os com a sequência didática proposta por Dolz, Noverraz e Schneuwly. O planejamento da sequência didática organizada para o desenvolvimento do projeto foi baseado no texto de opinião. A análise dos resultados obtidos neste trabalho permitiu que a autora atestasse a eficácia de um projeto organizado a partir de uma prática pedagógica que visa a contextualização da produção textual.

Outra investigação realizada por Souza (2003) com crianças da préescola à primeira série do ensino fundamental revelou que as crianças são capazes de produzir textos de opinião, mas nem sempre estão dispostas a escrevê-los. Outro ponto de destaque foi a 
constatação na "produção de texto um processo irregular, descontínuo, heterogêneo e permeado de avanços e retrocessos - um dia o texto tem legibilidade, no outro não pode ser lido" (SOUZA, 2003, p. 174).

Em um primeiro estudo, realizado por Azevedo (2002), a autora verificou que as crianças de nove anos que participaram da sua pesquisa são capazes de apresentar um discurso argumentativo de acordo com o padrão clássico da retórica, composto por introdução/proposição, descrição por meio de exemplificação, provas/refutação e conclusão. De acordo com Azevedo, nesta idade as crianças são capazes de organizar o discurso conforme as fases de composição das sequências argumentativas e explicativas que são utilizadas a favor do ponto de vista que se defende; selecionam e expõem argumentos diversificados, sendo os mais frequentes: 0 pragmático, o de finalidade e o de comparação; conhecem os operadores argumentativos de acordo com a fase da argumentação, ou seja, introduzem as premissas, realizam transições de ideias utilizando diversos conectivos, como: "pois", "porque", "além disso", etc. Essas crianças também marcam oposições por meio do uso do "mas"; utilizam orações concessivas, inserindo exemplos para apoiar os pontos de vista apresentados e algumas vezes elaboram conclusões com operadores adequados. Portanto, são capazes de empregar elementos coesitivos que contribuem para a coerência do texto.

Prosseguindo suas investigações, em 2009, Azevedo investigou os recursos discursivo-argumentativos presentes nos textos de participantes do ENEM/2004. A análise revelou dados preocupantes, ou seja, muitos dos alunos não estavam preparados para realizar todas as exigências linguísticas concernentes ao texto argumentativo. Ao comparar os dados dessa investigação aos resultados da pesquisa anteriormente realizada (AZEVEDO, 2002), a autora verificou que os jovens dominam os mesmos recursos linguísticos identificados nas crianças de nove anos. Esses dados permitiram Azevedo inferir que o longo período em que alunos brasileiros permanecem na escola não garante uma evolução em suas produções textuais argumentativas.

De outra parte, Pinheiro e Leitão (2007) analisaram produções de alunos da $2^{a}$ série e $5^{a}$ série do ensino fundamental e de estudantes do primeiro ano de um curso universitário. As autoras investigaram em que medida a consciência/conhecimento da estrutura prototípica de textos argumentativos exerce impacto sobre os elementos desta estrutura que os estudantes incorporam em seus textos. Os resultados obtidos mostraram que a apresentação de ponto de vista e justificativa foram os elementos considerados indispensáveis, enquanto a antecipação de contra-argumentos foi identificada como relevante para o objetivo persuasivo do texto apenas quando eram rebatidos. Revelam ainda que outros fatores, que não a consciência 
da estrutura prototípica do texto argumentativo (p.ex.: o papel do elemento no convencimento do destinatário - objetivo persuasivo) interferem na decisão do escritor de incluir, ou não incluir, num texto todos os elementos concernentes à estrutura argumentativa.

Em publicação recente, Rocha (2012) apresentou uma análise sobre as atividades didáticas de textos argumentativos escritos na coleção Português: Linguagens, dos autores William Roberto Cereja e Thereza Cochar Magalhães, destinada ao ensino médio. O objetivo do trabalho foi verificar como a obra didática ensina a produzir textos argumentativos escritos. De acordo com a autora, a obra privilegia e trabalha o conteúdo do texto e os aspectos prescritivos da língua sem contemplar os elementos da esfera original de produção, circulação e recepção desse tipo de texto. Em síntese, as sequências didáticas sugeridas não possibilitam ao aluno vivenciar as práticas sociais da escrita argumentativa. A partir dos resultados de sua análise, a autora propõe a adoção da perspectiva dialógica no encaminhamento teórico-metodológico para o ensino da escrita argumentativa, destacando o artigo de opinião e a perspectiva da construção de sentidos por parte do aluno.

Realizar investigações empíricas para verificar as hipóteses formuladas a partir do estudo das produções teóricas dos autores revisados, se constitui em uma agenda de pesquisa promissora. Entretanto, neste artigo, apenas uma hipótese será examinada, ou seja, hipotetizou-se que há uma relação entre o domínio das habilidades metacontextuais (coerência e coesão) e o desempenho na produção de textos de opinião por alunos do 5 o ano do ensino fundamental. Nesta perspectiva, delimitou-se como objetivo deste estudo identificar e descrever o uso de operadores organizacionais de coesão e a coerência em textos de opinião de escolares de 5o ano do Ensino Fundamental.

Em decorrência da diversidade de sentidos que se pode atribuir ao termo metacontextual, considera-se relevante explicitar o sentido que Ihe é empregado neste artigo. O termo metacontextual designa a habilidade de se refletir, analisar e manipular elementos intratextuais $^{2,}$ nas suas relações com o conjunto de circunstâncias intertextuais ${ }^{3,}$ pelas quais se produz uma mensagem, objetivando garantir a compreensão.

\section{Método}

Esta pesquisa caracteriza-se como exploratório-descritiva e teve um enfoque qualitativo.

Participantes

Participaram da pesquisa dezoito alunos que frequentavam o 5o ano do ensino fundamental de uma escola da rede pública municipal. 
Optou-se por realizar a investigação em uma escola de pequeno porte, que se localiza em um bairro periférico e de baixo poder aquisitivo, cujos alunos não se destacavam em provas nacionais.

Na turma dos participantes, há muitos casos de reprovação. Entre os dezoito alunos com idades variando entre 10 e 14 anos ( $d p=1,35$ ), três deles foram reprovados em um ano escolar, três alunos foram reprovados duas vezes (em dois anos escolares), um aluno foi reprovado três anos escolares (permanecendo dois anos em cada ano escolar) e um aluno foi reprovado quatro vezes, cursando dois anos consecutivos em cada ano escolar. Em suma, do total de dezoito alunos, oito deles apresentam histórico de reprovações escolares. Para exemplificar as produções dos participantes serão utilizados textos de uma aluna que não apresenta histórico de reprovação (Carol), e textos de uma aluna de inclusão (Luma) ${ }^{4}$.

\subsection{I nstrumento}

Como instrumento de intervenção e procedimento principal para a coleta de dados, foi eleita a realização da sequência didática fundamentada principalmente em Dolz, Noverraz e Schneuwly (2004), e em Bronckart (1999). Salienta-se que a sequência didática "é um conjunto de atividades escolares organizadas, de maneira sistemática, em torno de um gênero textual oral ou escrito" (DOLZ; NOVERRAZ; SCHNEUWLY, 2004, p. 97).

De acordo com Dolz, Noverraz e Schnewly (2004), a sequência didática tem por finalidade possibilitar aos alunos a realização de tarefas seguindo etapas de produção de um determinado gênero. $O$ modelo de trabalho segue, portanto, quatro fases assim definidas: a primeira etapa é a apresentação da situação de produção do gênero a ser trabalhado; a segunda etapa refere-se à primeira atividade de produção, denominada produção inicial, que serve tanto como um esboço textual para os alunos, que posteriormente farão ajustes neste texto, quanto para o professor avaliar o conhecimento que os alunos já possuem sobre o gênero; a terceira etapa é composta por módulos (subdivididos em oficinas), que podem ser vários e são elaborados conforme as necessidades dos alunos; a quarta etapa é a produção final, na qual os alunos evidenciam o que aprenderam ao longo dos módulos. Nessa última etapa, os alunos podem realizar uma reescrita a partir da análise de sua produção inicial.

\subsection{Aplicação do instrumento: procedimentos adotados}

O projeto de pesquisa foi submetido e aprovado pela Secretaria Municipal de Educação de São José dos Pinhais-PR. Antes do início do estudo, obteve-se autorização de um dos pais ou responsáveis pelos alunos por meio do Termo de Consentimento Livre e Esclarecido e o 
Termo de Assentimento assinado pelos próprios participantes. Ambos os termos garantiam a participação voluntária dos alunos nas atividades e a possibilidade de divulgação dos resultados respeitandose seu anonimato.

A aplicação do instrumento de intervenção (sequência didática) implicou a realização de diversas atividades elaboradas especificamente para este estudo. A princípio, houve a apresentação da situação de produção do texto de opinião e os participantes foram incentivados a realizarem a produção inicial. Esta atividade partiu de uma simulação em que eles deveriam produzir um texto de opinião para um suposto jornal da escola (Jornal Planeta Infantil) a partir da seguinte manchete:

Uma criança de oito anos de idade apanhou do pai nesta quinta-feira, 02 de agosto de 2011. Segundo o pai, ele sempre bate no filho porque o menino não respeita as suas ordens, tira notas baixas na escola, e está sempre aprontando alguma coisa. Desta vez, a surra foi por causa de desobediência. Esse é mais um caso de pais que batem em filhos, mas uma pergunta incomoda: bater nas crianças

\section{resolve?}

Dando continuidade à sequência didática foram realizados três módulos: o primeiro módulo, Conhecendo o texto argumentativo/de opinião, foi subdividido em cinco oficinas; o segundo módulo, Analisando as produções - estrutura, coesão e coerência textuais, foi subdividido em duas oficinas; e no terceiro módulo, Produzindo textos de opinião, houve apenas uma oficina de produção textual. Observase que foram realizadas ao todo oito oficinas com a finalidade de que os alunos se apropriassem da estrutura do texto argumentativo e compreendessem o uso dos elementos coesitivos para auxiliar na coerência textual.

Destaca-se que durante as oficinas, para o estudo dos elementos coesitivos por conexão, os alunos receberam uma tabela contendo palavras e expressões concernentes à coesão conectiva (operadores argumentativos e operadores organizacionais) com a finalidade de auxiliar o uso desses elementos nas suas produções a partir da reflexão sobre o efeito que cada um deles produz na compreensão do texto pelo interlocutor. Os alunos foram incentivados a refletirem sobre os efeitos do uso dos operadores argumentativos e operadores organizacionais em diferentes textos, inclusive em produções realizadas por eles.

$\mathrm{Na}$ última etapa da sequência didática, denominada por Dolz, Noverraz e Schnewly (2004) de produção final, os alunos realizaram a revisão e a reescrita da produção inicial.

Neste artigo serão analisadas e comparadas as produções iniciais com as produções finais (textos da reescrita) dos participantes. O motivo desta escolha ocorreu em função da produção inicial ter o efeito de um pré-teste e a reescrita a função de um pós-teste, realizado após 
todos os procedimentos da intervenção estabelecidos na sequência didática.

\section{Apresentação e análise dos resultados}

Os dados foram analisados considerando-se duas etapas: primeiro, foi realizada uma análise geral de todos os textos, tomados individualmente como produções singulares do gênero, em que se verificou a ocorrência do uso de palavras e expressões relativas à coesão conectiva; segundo, foi realizada uma análise descritiva do desempenho nas duas produções (texto inicial e reescrita) dos textos de opinião produzidos por duas alunas (Carol e Luma) com o intuito de exemplificar e sustentar a discussão. As produções de Carol e Luma foram selecionadas por possibilitarem a compreensão de movimentos dialógicos-argumentativos caracterizados pela comparação entre as organizações realizadas em dois momentos distintos. Assim, observa-se como o fenômeno de reescrita auxilia na (re)elaboração do texto argumentativo.

Destaca-se que os dados obtidos foram analisados em relação a dois fatores: a construção de conhecimento relativo ao uso de operadores argumentativos e de operadores organizacionais; e a atenção dada ao uso destes mesmos elementos coesitivos no momento da reescrita.

São apresentadas duas tabelas que apontam o encadeamento por conexão nas produções relativas à produção inicial e reescrita. Na Tabela 1 consta o uso de operadores argumentativos e a Tabela 2 mostra o uso de operadores organizacionais, considerando-se a frequência de emprego destes operadores nas produções iniciais dos alunos e na reescrita dessas produções que ocorreu após a intervenção.

\subsection{Uso de operadores argumentativos e a coerência textual:}

TABELA 1: FREQUÊNCIA DO USO DOS OPERADORES ARGUMENTATIVOS NAS PRODUÇÕES DOS ALUNOS

\begin{tabular}{ccc}
\hline OPERADORES ARGUMENTATI VOS & \\
\hline & $\begin{array}{c}\text { Produção } \\
\text { Inicial }\end{array}$ & Reescrita \\
\hline
\end{tabular}

Oposição: mas, porém, contudo

Causa: porque, pois* , já que, desde que

$9 \quad 9$

Conclusão: logo, assim, portanto*

Comparação: mais do que, menos do que, assim como,

tal qual

Condição: se, a menos que, a não ser que

Finalidade: para que, a fim de que

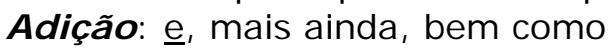


Exclusão: nem

Alternativa: ou

2

As conjunções sublinhadas foram aquelas que apareceram nos textos.

*Apareceu somente em um texto.

Os dados coletados revelaram que as conjunções (operadores argumentativos) mais usadas na produção inicial foram: conjunção aditiva "e"; e a conjunção causal "porque". Observa-se um movimento de diminuição da conjunção causal "porque" na reescrita desse mesmo texto. Não houve ocorrência do uso de conjunções que expressam comparações e finalidade. A frequência do uso da conjunção "se" na produção inicial manteve-se na reescrita.

De acordo com os dados desta tabela, verifica-se que os alunos usam, basicamente, quatro tipos de organizadores argumentativos: "mas", "e", "se", e "porque". Além disso, nota-se uma ocorrência digna de reflexão, ou seja, a incidência do uso da conjunção causal/explicativa "porque" tanto na produção inicial como na reescrita do texto. É importante salientar que a maioria dos alunos manteve na reescrita a sequência de grande parte do material linguístico do texto, preservando o plano textual no que se refere à estrutura prototípica. As modificações realizadas referem-se, principalmente, aos operadores argumentativos e a inclusão de operadores organizacionais metalinguísticos, o que será exemplificado mais adiante nos textos produzidos pela aluna Carol.

Uso de operadores organizacionais e a coerência textual:

TABELA 2: FREQUÊNCIA DO USO DOS OPERADORES ORGANIZACIONAIS NAS PRODUÇÕES DOS ALUNOS

\begin{tabular}{|c|c|c|}
\hline \multicolumn{3}{|c|}{ OPERADORES ORGANI ZACI ONAI S } \\
\hline \multicolumn{3}{|c|}{ Expressões que ajudam a reforçar ou esclarecer melhor a ideia que estamos apresentando } \\
\hline & $\begin{array}{l}\text { Produção } \\
\text { Inicial }\end{array}$ & Reescrita \\
\hline Por exemplo... & 1 & 1 \\
\hline Isto é... & $\varnothing$ & $\varnothing$ \\
\hline ou seja... & $\varnothing$ & $\varnothing$ \\
\hline Por outro lado... & $\varnothing$ & $\varnothing$ \\
\hline Quer dizer... & $\varnothing$ & $\varnothing$ \\
\hline Segundo fulano... & $\varnothing$ & $\varnothing$ \\
\hline Em outras palavras... & $\varnothing$ & $\varnothing$ \\
\hline \multicolumn{3}{|c|}{ Expressões que anunciam o ponto de vista do autor } \\
\hline Diante de tudo... & $\varnothing$ & 2 \\
\hline Em primeiro lugar... & $\varnothing$ & 4 \\
\hline Há diferentes opiniões sobre... & $\varnothing$ & 1 \\
\hline O tema que eu vou tratar... & $\varnothing$ & $\varnothing$ \\
\hline Para comecar, direi... & $\varnothing$ & 3 \\
\hline Falaremos sobre... & $\varnothing$ & $\varnothing$ \\
\hline Na minha opinião... & 2 & 6 \\
\hline No meu ponto de vista... & $\varnothing$ & $\varnothing$ \\
\hline Com certeza... & $\varnothing$ & 2 \\
\hline Parece-me que... & $\varnothing$ & $\varnothing$ \\
\hline \multicolumn{3}{|c|}{$\begin{array}{l}\text { OPERADORES ORGANI ZACI ONAIS DE TEMPO E ESPAÇO } \\
\text { Expressões que dão noção de tempo e de espaço }\end{array}$} \\
\hline Em primeiro lugar... & $\varnothing$ & 2 \\
\hline Em segundo lugar... & $\varnothing$ & 1 \\
\hline Como veremos... & $\varnothing$ & $\varnothing$ \\
\hline
\end{tabular}


Como vimos...

Neste ponto...

Aqui na primeira parte...

\begin{tabular}{ll}
$\varnothing$ & 1 \\
$\varnothing$ & $\varnothing$ \\
$\varnothing$ & $\varnothing$ \\
\hline
\end{tabular}

Da análise dos operadores organizacionais, a tabela 2 revela que não houve, no transcorrer da investigação, uma alteração significativa no uso de expressões que ajudam a reforçar ou esclarecer melhor a ideia que o escritor está apresentando. Encontrou-se a expressão “Por exemplo" usada por uma aluna na produção inicial e mantida por ela na reescrita. Quanto às expressões que dão noção de tempo e espaço, a que apareceu com maior frequência foi "Em primeiro lugar...", principalmente na reescrita. E, a expressão "Em segundo lugar..." apareceu na reescrita de alguns alunos.

Destaca-se que a expressão "em primeiro lugar" foi computada tanto na categoria de expressões que dão noção de tempo como na categoria que dá noção de espaço, dependendo de como ocorreu à sequência do texto, ou seja, quando apareceu em outro parágrafo expressões pertencente a determinado grupo linguístico, como: em "segundo lugar", ou, "como vimos". Entretanto, nos casos em que essa expressão anunciou a tomada de posição do aluno em relação ao tema, computou-se como expressão que exprime o ponto de vista do autor.

\subsection{Apresentação e análise das produções de Carol e de Luma}

Primeiramente, serão analisadas e discutidas as produções (inicial e reescrita) de Carol enfatizando o uso que ela fez de operadores argumentativos e a relação entre o emprego dos mesmos e a coerência textual. Dando continuidade, analisam-se e se discutem os textos (produção inicial e reescrita) de Luma, cujo destaque será para - uso que esta aluna fez de operadores organizacionais e para a relação entre o uso destes operadores e a coerência textual.

As produções de Carol:

Produção inicial de Carol.

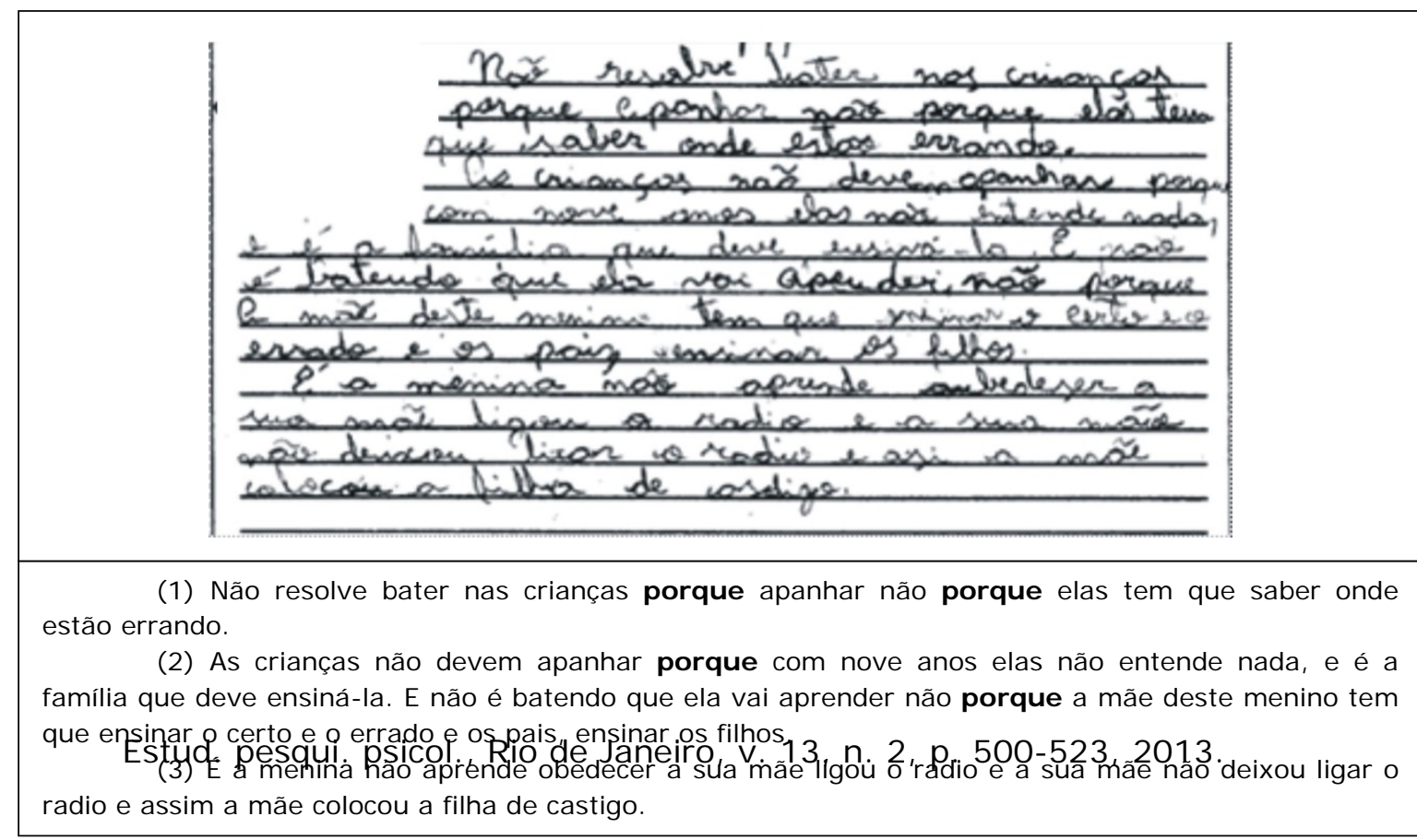


Verifica-se que Carol realiza um plano textual que se caracteriza como um discurso-argumentativo no que se refere à tomada de posição diante do tema e na construção de justificativas. A aluna evidencia o seu posicionamento crítico, contudo, sente dificuldade na organização das ideias fazendo com que a sua escrita apresente um sequenciamento coesivo que não contribui para a coerência. Na introdução do texto, o uso da conjunção "porque" chega a comprometer possíveis inferências, a depender da competência textual do interlocutor. Este procedimento trouxe consequências ao nível da coerência fazendo com que partes desse texto possam ser coerentes para uns, e não para outros. Todavia, isso não foi suficiente para conferir inconsistência argumentativa quando se toma o texto na íntegra.

No parágrafo seguinte, a aluna busca um domínio na organização interfrástica fazendo o uso do operador argumentativo causal/explicativo "porque". No último parágrafo, a aluna inclui um relato e não o conecta aos argumentos anteriores. A ausência de uma conexão explícita e de uma organização para expor essas ideias atrapalha o interlocutor na construção de sentido. O encerramento do texto com uma narrativa possibilita indagar se a aluna sentiu dificuldade em articular as informações utilizando operadores argumentativos; se a sua dificuldade decorre do fato de esse ser o seu primeiro texto de opinião, portanto, desconhece a estrutura argumentativa; ou se a sua dificuldade refere-se a poucas informações concernentes ao tema para serem discutidos no interior do texto. Ou ainda, se todos esses fatores, tomados em conjunto, dificultam a progressão temática por meio de processos articuladores do texto.

Na sequência, analisa-se a reescrita desse texto comparando-a com a produção inicial:

Reescrita de Carol:

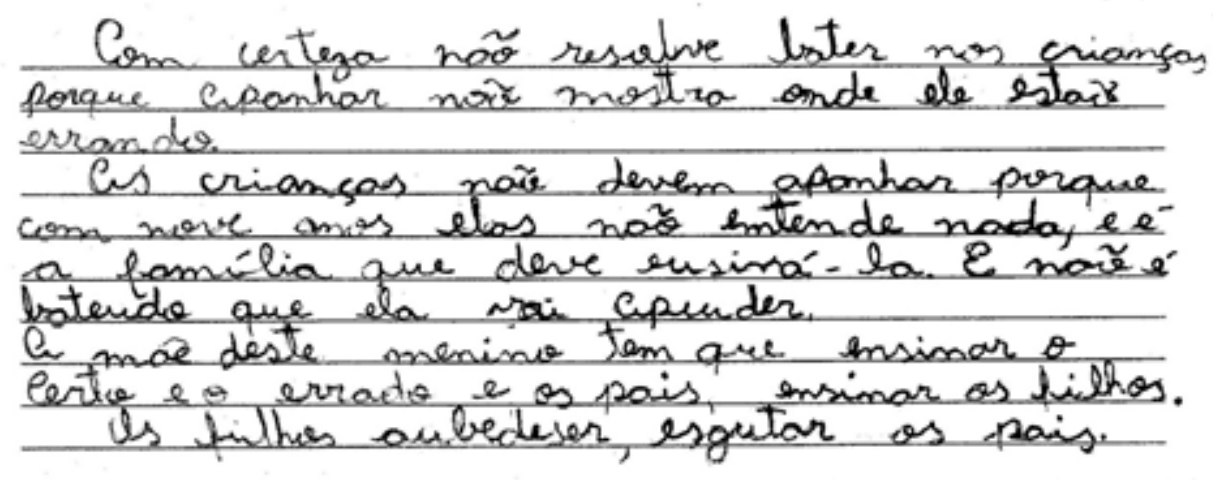
errando.

(1) Com certeza não resolve bater nas crianças porque apanhar não mostra onde ele estão

(2) As crianças não devem apanhar porque com nove anos elas não entende nada, e é a família que deve ensiná-la. E não é batendo que ela vai aprender.

(3) A mãe deste menino tem que ensinar o certo e o errado e os pais, ensinar os filhos.

(4) Os filhos aubedeser, esgutar os pais. 
Por meio da análise da reescrita de Carol, percebe-se uma evolução qualitativa no que diz respeito à produção textual. Esse resultado possibilita supor uma apreensão das dimensões linguísticas trabalhadas na intervenção. Tais conhecimentos não foram detectados na produção inicial.

Nessa atividade, a aluna mantém a ideia central defendida por ela: Não se deve bater em crianças porque não resolve. Para alcançar melhorias, ela elimina as partes que julga serem desnecessárias e reorganiza a ideia central usando recursos linguísticos adequadamente. Com isso, estabelece uma continuidade de sentidos entre os elementos inscritos no texto, garantindo a tessitura. Carol explicita o seu ponto de vista iniciando com um operador organizacional metalinguístico, "com certeza", e o justifica conectando 0 ponto de vista à justificativa com o operador argumentativo "porque". Comparando-se o primeiro parágrafo do texto inicial com o primeiro parágrafo da reescrita, observa-se que Carol elimina as partes que não expressavam sentido lógico inclusive o "porque" excedente nessa parte do texto na produção inicial.

A reescrita do texto de Carol flui com coerência e o desenvolvimento textual caracteriza-se por dois aspectos: o primeiro refere-se ao uso mais adequado de marcas linguísticas; e o segundo aspecto está relacionado com o fato de a aluna ter desdobrado o segundo parágrafo da produção inicial em dois parágrafos na reescrita, eliminando uma conjunção causal/explicativa "porque". Consequentemente, a sequência de ideias passa a transcorrer de modo que a articulação entre os enunciados colabora para a realização da progressão temática. Essa decisão de Carol não apenas evita a repetição desnecessária de um operador argumentativo, como desconecta duas sequências frásicas que se suplementam no texto, mas não são complementares entre si. Com isso, amplia-se a dimensão compreensiva para o interlocutor ficando mais evidente 0 que a aluna está defendendo.

A fim de concluir, Carol elimina os enunciados que não correspondem com o encadeamento de suas ideias no discurso argumentativo. É interessante notar que a aluna apreendeu as características argumentativas identificando a inadequação de enunciados narrativos. Motivo pelo qual encerra o seu texto afirmando o seu discurso de que, se os pais ensinam as regras sociais sem o uso de atributos violentos, os filhos os obedecem e os escutam.

A reescrita de Carol é um bom exemplo para demonstrar melhoras na estrutura textual a partir do uso mais adequado de operadores argumentativos para o estabelecimento de sentido, facilitando a leitura para o interlocutor.

As produções de Luma: 
O texto que se verá adiante é um exemplo de produção em que a aluna conseguiu articular vários recursos linguísticos. Neste caso, buscou-se identificar as possíveis modificações no texto de Luma quanto ao uso de operadores organizacionais, quando esta realizou a reescrita da produção inicial.

Produção inicial de Luma:

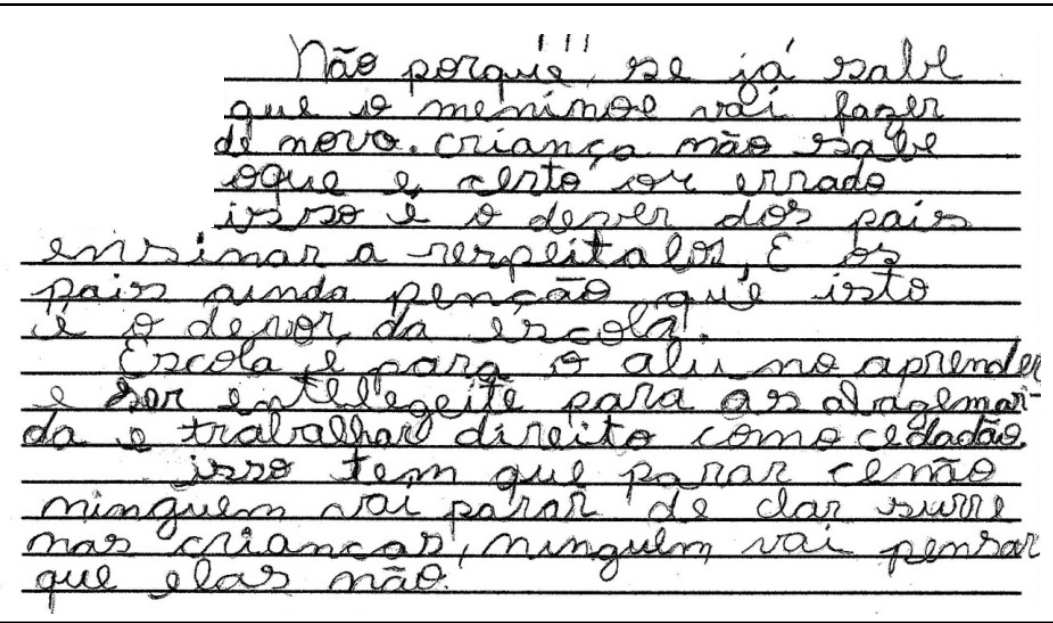

(1) Não porque, se já sabe que o meninoe vai fazer de novo. criança não sabe oque e certo ou errado isso é o dever dos pais ensinar a respeitalos, E os pais ainda penção que isto é o devor da escola. cedadão.

(2) Escola é para o aluno aprender e ser entelegeite para as alagemarda e trabalhar direito como elas não.

(3) isso tem que parar cenão ninguem vai parar de dar surre nas criancas, ninguem vai pensar que

Reescrita da produção inicial de Luma

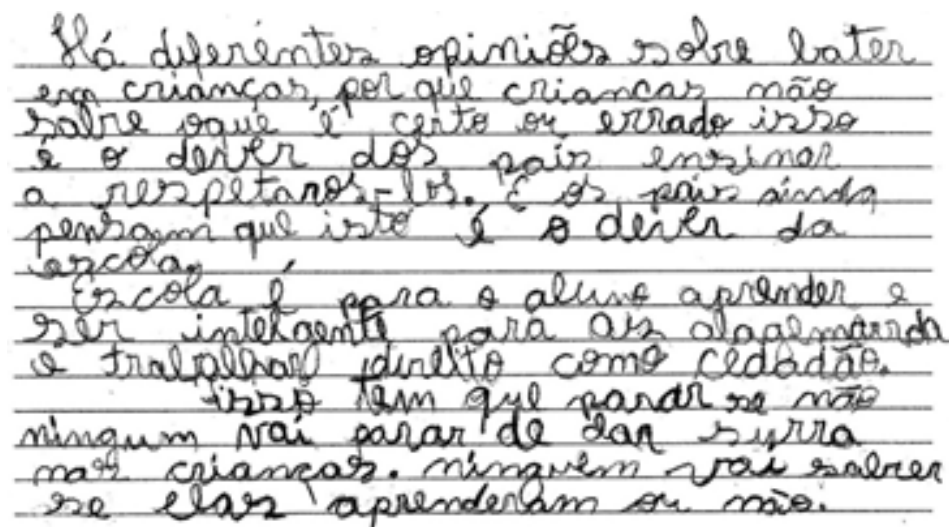

(1) Há diferentes opiniões sobre bater em crianças, por que criancas não sabe oque é certo ou errado isso é o dever dos pais ensinar a respetaros-los. E os pais ainda pensam que isto é o dever da escola.

(2) Escola é para o aluno aprender e ser intelgente para as alagemarrda e trabalhar direito como cedadão.

(3) isso tem que parar se não ningum vai parar de dar surra nas crianças. ninguem vai saber se elas aprenderam ou não. 
A introdução da produção inicial de Luma estrutura-se numa condição responsiva à pergunta motivadora da produção (Bater nas crianças resolve?). Assim, a ação de linguagem desempenhada pela aluna não está inadequada, apenas atende à realidade de aprendizados a qual está (esteve) inserida (emitir opinião e justificá-la).

A originalidade desse texto está na inserção de argumentos que desautorizam os pais a atribuírem responsabilidade de ensinar as condutas sociais (valores de civilidade) à escola. Pode-se inferir a partir dos argumentos de Luma, que a escola é para se aprender, para ficar inteligente, e, como consequência, atuar na sociedade na condição de um cidadão que trabalha direito. Porém, a ação linguístico-discursiva fica comprometida diante da incorporação deste tema tão polêmico, consequentemente, não há um encadeamento discursivo linear.

Neste sentido, ao invés de prosseguir à discussão do tema proposto, a aluna declina-se para justificar um tema novo inserido por ela. Veja-se que ela não consegue alinhavar o seu discurso em decorrência da ausência, ou do uso inadequado, de marcas linguísticas. Não houve, em todo o texto, a inclusão de um operador organizacional.

Para compreender a conclusão desse texto, é necessário um retorno à introdução com a finalidade de resgatar a discordância explicitada (o que precisa parar?), ou fazer inferências a partir das orações conseguintes. Além disso, Luma encerra o seu discurso deixando uma oração incompleta.

Na reescrita, um olhar desatento ou superficial acerca da produção realizada, provavelmente resultaria em conclusões precipitadas nas quais poderia ser dito que a aluna evoluiu muito pouco em relação ao que se espera de um aluno no final de uma intervenção. No entanto, perceber as sutilezas contidas na ação de linguagem desempenhada pela aluna representa a compreensão de que as mudanças no processo ensino-aprendizagem podem ocorrer sutilmente e que a qualidade destas mudanças é relevante por desvelar melhorias no desempenho. Para uma maior compreensão, comparam-se os parágrafos iniciais observando que a estrutura do texto foi modificada em função da inclusão de um articulador argumentativo: "Há diferentes opiniões sobre...". Ainda que a continuidade do enunciado não corresponda com as expectativas discursivas que esse operador metalinguístico desencadeia na ação comunicativa. Por isso, acreditase que Luma tinha pouca compreensão do impacto que um operador metalinguístico poderia gerar no interlocutor. Contudo, a inserção deste na escrita pode caracterizar dois fenômenos distintos: o primeiro deles é uma suposta tentativa da aluna de cumprir com as exigências escolares, assim, inseriu a expressão porque tem que ser usado neste gênero textual; o segundo fenômeno, diz respeito à 
utilização de conhecimentos novos que estão sendo apropriados pela aluna. Esta segunda interpretação é adotada nessa análise como o fenômeno mais provável visto que a aluna compromete-se com a atividade quando reorganiza o enunciado retirando os excedentes e melhorando a ortografia.

$\mathrm{Na}$ comparação entre as duas produções relativas ao segundo parágrafo, não há indícios de alterações, mantendo-se inclusive os problemas ortográficos. Já na conclusão, Luma revisita a sua produção inicial e percebe necessidades de alteração. Dessa forma, verifica que a sua conclusão não está completa e fecha o enunciado introduzindo a palavra faltante.

Tais sutilezas podem aparentar pequenas e até insignificantes melhorias quando se pensa na construção de uma autonomia na produção argumentativa escrita, mas elas representam muito neste momento específico, para esta aluna. Bronckart (1994) salienta que existem muitas decisões a serem tomadas numa ação de linguagem que requerem competência do agente produtor para executá-las. Portanto, para Luma, coordenar tantas informações e decisões revela uma evolução no empreendimento concernente à produção de texto argumentativo.

\section{Discussão dos dados e conclusão}

Sabe-se que a produção de texto de opinião envolve não apenas o conhecimento do tema a ser discutido como as características do gênero discursivo em questão e as especificidades linguísticas inerentes ao tipo textual. Pensando assim, analisou-se o emprego de operadores argumentativos e dos operadores organizacionais comparando-se as produções iniciais dos alunos com a reescrita dessas produções que ocorreu após a intervenção.

A análise das operações de reelaboração textual revelou que as crianças, respeitadas as singularidades cognitivas e às condições específicas de produção, são capazes de desenvolver habilidades metacontextuais que as auxiliam na produção argumentativa.

Os dados corroboram as pesquisas de Azevedo (2002) e a de Souza (2003) no que diz respeito à possibilidade de crianças aprender a produzir textos de opinião.

Observou-se que um dado segmento do texto pode ser alterado e reconfigurado a partir de um exame criterioso do escritor, com base em instruções formais. Tal empreendimento torna-se um exercício privilegiado para a reconstrução de conhecimentos linguísticos e automonitoramento no ato de produzir textos. A observação de casos em que não houve alterações não autoriza, entretanto, a conclusão de que houve, ou não houve, o desenvolvimento de habilidades metacontextuais nestes alunos. A inclusão/exclusão de um dado 
elemento linguístico em uma reescrita nem sempre corresponde ao conhecimento da estrutura da língua e pode estar condicionada a outros fatores. Pode-se dizer que os resultados obtidos neste trabalho corroboram tanto os dos estudos de Souza (2003) quanto os dos estudos de Pinheiro e Leitão (2007) quando estes revelam a irregularidade e descontinuidade presente no processo de aprendizado da escrita argumentativa.

A análise dos textos mostrou que as alunas (autoras) apreenderam diversos operadores organizacionais. Em outras palavras, verificou-se nos textos produzidos após a intervenção que as alunas conseguiram um encadeamento por conexão, isto é, articularam elementos coesitivos, aperfeiçoando a tessitura dos seus textos e instituindo melhores relações semânticas. Nesses termos, reforça-se a ideia de que a gramática não deva ser trabalhada dissociada da sua finalidade linguística. As alunas, apresentando essa apreensão dos operadores organizacionais, confirmam que, quando há entendimento acerca da finalidade linguística de um termo, ou expressão, o seu emprego torna-se mais coerente, viabilizando melhor desempenho na textualização. Com isso, concorda-se com Rocha (2012) no que se refere à proposição de um encaminhamento metodológico na perspectiva enunciativo-discursiva para o ensino da escrita argumentativa. Destaca-se que, para essa autora, as atividades de leitura, de produção e de análise de textos devem estar articuladas com os aspectos gramaticais e prescritivos da língua a partir da reflexão em torno de uma prática social.

Os dados obtidos evidenciaram que o processo de ensinoaprendizagem do texto de opinião (texto argumentativo) requer mais do que a simples compreensão do escritor acerca da organização textual. Destaca-se a importância dos alunos entenderem que a produção desse gênero deve partir de um tema controverso no qual se assume um ponto de vista, apresentam-se dados que sustentam a posição assumida, apontam-se contraposições, com vistas no convencimento do interlocutor. Entretanto, é preciso aprender também a utilizar os operadores argumentativos e organizacionais de modo a articular adequadamente os enunciados, garantindo a coesão textual e a coerência com o intuito de evitar a fragmentação enunciativa, como destacou Bränkling (2000).

A partir do que foi analisado nos textos das alunas Carol e Luma, reafirma-se o princípio de que os mecanismos formais de uma língua permitem que sejam instauradas as relações de sentido em um texto. Contudo, os elementos linguísticos devem ser trabalhados (apresentados e discutidos com os alunos) de forma contextualizada para que o aprendiz de produção textual compreenda a aplicabilidade dos termos.

Este estudo revelou que no fluxo das interações discursivas a prática social da língua exige dos indivíduos uma interação/integração com 
palavras carregadas de sentido, de conteúdo ideológico e vivencial, conforme defende a teoria Bakhtiniana. Desta forma, acredita-se que as práticas pedagógicas não devem reduzir a escrita à reflexão da língua como um sistema abstrato de normas dissociado da sua funcionalidade social e comunicativa.

Enfim, ao analisar o encadeamento por conexão na produção dos textos de opinião das duas alunas, conclui-se que os textos produzidos revelam progresso nas suas habilidades metalinguísticas. Portanto, é possível questionar se a complexidade das operações linguísticas envolvidas na produção textual é inerente ao tipo de texto argumentativo, ou se está intrinsecamente relacionada com a forma como essas operações são tratadas no âmbito das práticas pedagógicas.

Salienta-se que o uso de conectivos deve ser trabalhado constantemente, sendo retomado sempre que houver oportunidade. Desta forma, pode ser que se alcance resultados mais satisfatórios em propostas longitudinais. $E$, quem sabe, sejam alcançadas mudanças mais expressivas na produção de textos argumentativos, alterando o quadro apresentado nas pesquisas de Azevedo (2009).

Por último, destacando o caráter sócio-cognitivo do desenvolvimento da linguagem - o qual ocorre a partir de ações compartilhadas -, os resultados deste estudo mostraram que privilegiar as atividades de discussão, revisão e reelaboração direcionada para o uso dos articuladores argumentativos surtiram resultados satisfatórios nas produções analisadas.

\section{Considerações Finais}

A presente investigação, embora tenha incorporado um trabalho de intervenção, não fornece resultados que possam ser considerados conclusivos, tendo em vista, principalmente, o número reduzido de participantes. Contudo, três pontos merecem ser enfatizados.

O primeiro ponto diz respeito à contribuição que uma proposta de encaminhamento metodológico realizado a partir de uma sequência didática pode trazer para a área. A sequência didática revelou-se eficaz tanto como instrumento de intervenção pedagógica, quanto como instrumento de investigação. Nesses termos, pode auxiliar o professor a pensar sobre como o aluno constrói o conhecimento durante as produções textuais. Pode, ainda, servir para a contínua avaliação das aprendizagens e dificuldades reveladas pelos alunos, subsidiando reelaborações no planejamento pedagógico. E, como instrumento de pesquisa, foi capaz de explicitar os efeitos de uma intervenção com finalidades específicas.

O segundo ponto está relacionado com a proposta de realizar uma produção inicial antes de qualquer instrumentalização teórica dos 
alunos e, após a intervenção, realizar uma reescrita desta produção inicial. Este procedimento metodológico revelou-se como uma estratégia metacontextual que propiciou aos alunos uma maior capacidade de análise e de manipulação deliberada dos elementos intratextuais conforme o conjunto de circunstâncias intertextuais.

Como terceiro ponto, destaca-se a importância e necessidade de outras pesquisas que possam analisar não apenas os produtos iniciais e finais (após intervenção), tendo em vista a relevância de se analisar o processo construtivo dos alunos.

As limitações deste estudo - principalmente relativas ao tempo de intervenção e número de participantes - sugerem a necessidade de que outras pesquisas possam somar esforços para se conhecer melhor os processos de (re)organização de conhecimentos a partir de habilidades metacontextuais.

Assim, os resultados desta investigação levantam várias questões, embora as principais refiram-se às possibilidades de desenvolvimento da habilidade metacontextual nos anos iniciais do ensino fundamental, à relação entre estas habilidades e à capacidade de produção escrita, e às implicações educacionais dos resultados destas pesquisas.

\section{Referências}

ADAM, J-M. Les textes: types et prototypes. Paris: Nathan, 1992. AMORIM, K. S.; ROSSETTI-FERREIRA, M. C. Dialogismo e a invenção de processos desenvolvimentais humanos. Paidéia, Ribeirão Preto, 18(40), 235-250, 2008.

AZEVEDO, I. C. M. A argumentação no exame nacional do ensino médio: percursos discursivos seguidos por jovens em processo de formação. 2009. 243f. Tese (Doutorado em Estudos do Discurso em Língua Portuguesa - Retórica e Argumentação). Universidade de São Paulo, Faculdade de Filosofia, Letras e Ciências Humanas (FFLCH), 2009.

AZEVEDO, I. C. M. O lugar da argumentação na escrita infantil: análise discursiva e proposta metodológica. 2002. $232 \mathrm{f}$. Dissertação não publicada (Mestrado em Comunicação e Letras) Universidade presbiteriana Mackenzie, São Paulo, 2002.

BAKHTIN, M. Estética da criação verbal. 5. ed. São Paulo: Martins Fontes, 2010.

Marxismo e filosofia da linguagem. São Paulo, SP: Hucitec. (Original Work published 1929), 1995.

BRANDÃO, H. H. N. Escrita, leitura, dialogicidade. In: B. BRAIT (Ed.), Bakhtin, dialogismo e construção de sentido (p. 281-290). Campinas, SP: Editora da Universidade Estadual de Campinas, 1997. 
BRÄNKLING, K. L. Trabalhando com artigos de opinião: re-visitando o eu no exercício da (re)significação da palavra do outro. In: ROJO, R. (org.) A prática da linguagem em sala de aula: praticando os PCNs. São Paulo: EDUC/ Campinas: Mercado de Letras, 2000.

BOFF, O. M. B.; KÖCHE, V. S.; MARINELLO, A. F. (2009) O gênero textual artigo de opinião: um meio de interação. ReVEL, vol. 7, n. 13. [www.revel.inf.br].

BRONCKART, J. P. Atividade de linguagem, textos e discursos: por um interacionismo sócio-discursivo. São Paulo: EDUC, 1999. DOLZ, J.; NOVERRAZ, M.; SCHNEUWLY, B. Sequências didáticas para o oral e a escrita: apresentação e um procedimento. In: SCHNEUWLY, B.; DOLZ, J. \& COLABORADORES. Gêneros orais e escritos na escola. Tradução e organização de R. H. R. ROJO e G. S. CORDEIRO. Campinas: Mercado de Letras, 2004.

GOMBERT, J. E. Metalinguistic development. Great Britain: BPCC Wheatons Ltd, 1992.

$\mathrm{KOCH}$, I. G. V. Desvendando os segredos do texto. 4a ed. São Paulo: Cortez, 2002.

A coesão textual. 20a ed. São Paulo: Contexto, 2010.

Introdução à linguística textual. $2^{a}$ ed. São Paulo: WMF Martins Fontes, 2009.

$\overline{2} \overline{1} \overline{1}$.

Argumentação e linguagem. São Paulo: Cortez Editora,

KOCH, I. G. V.; TRAVAGLIA, L. C. A. A coerência textual. São Paulo: Contexto, 2007.

KÖCHE, V. S.; BOFF, O. M. B.; PAVANI, C. F. Prática textual: atividades de leitura e escrita. Petrópolis: Vozes, 2006.

LEITÃO, S. Composição textual: especificidade da escrita argumentativa. In: J. CORRÊA, A. SPINILLO, S. LEITÃO (Orgs.). Desenvolvimento da linguagem: escrita e textualidade. Rio de J aneiro: FAPERJ/NAU, 2001.

. Argumentação e desenvolvimento do pensamento reflexivo. In: Psicologia: Reflexão e Crítica, Porto Alegre, 20(3), 454-462, 2007.

- O manejo de contra-argumentos na escrita argumentativa infantil. In: Temas em Psicologia da SBP, Ribeirão Preto, v. 08, n. 1,79-92, 2000.

LEITÃO, S. \& BANKS-LEITE, L. Argumentação na linguagem infantil: algumas abordagens. In: DEL RÉ, $A$. Org) Aquisição da linguagem - uma abordagem psicolingüística. SP: Contexto, p. 45-61, 2006. LIMA, M. C. C. Desenvolvimento da escrita argumentativa: os efeitos de um ensino sistemático da argumentação para alunos de $5 \underline{a}$ série do Ensino Fundamental. 88f. Dissertação de Mestrado não publicada. Universidade Federal do Paraná: setor de educação, Programa de Pós-Graduação em Educação, 2006. 
MARCUSCHI, A. L. Gêneros textuais: definição e funcionalidade. In: DIONÍSIO, A.; MACHADO, A. R.; BEZERRA, M. A. Gêneros textuais e ensino. Rio de J aneiro: Lucerna, 2002.

MARCUSCHI, A. L. Produção textual, análise de gêneros e compreensão. São Paulo: Parábola Editorial, 2008.

MARCUSCHI, L. A. Oralidade e Escrita. Comunicação apresentada na conferência de abertura no II Encontro Franco Brasileiro de ensino de língua. Natal, 1995.

PINHEIRO, R.; LEITÃO, S. Consciência da "estrutura argumentativa" e produção textual. Psicologia: Teoria e Pesquisa, Brasília, vol. 23, n.4, p. 423-431, 2007.

ROCHA, R. B. S. S. O ensino da escrita argumentativa na perspectiva dialógica. In: Bakhtiniana: Revista de Estudos do Discurso [online]. vol. 7, n.1, pp. 199-218, 2012.

SANTA-CLARA, A. O.; LEITÃO, S. A escrita como fórum dialógicoargumentativo de construção do conhecimento. Psicologia: Reflexão e Crítica, Porto Alegre, v. 24, n.2, 394-402, 2011.

SANTOS, S. L. (2005). A construção de argumentos no cotidiano. In: DIAS, M. G.; SPINILLO, A. (Orgs). Tópicos em Psicologia Cognitiva. - 2a ed.- Recife: Ed. Universitária da UFPE, 1996.

SANTOS, S. L. O desenvolvimento da escrita argumentativa. Arquivos Brasileiros de Psicologia, Rio de Janeiro, n 49, p. 23-42, 1997.

SPINILLO, A. G. A consciência metatextual. In: Mota, M. (org) Desenvolvimento Metalinguístico: questões contemporâneas São Paulo: Casa do Psicólogo, 2009.

SOUZA, L. V. As proezas das crianças em textos de opinião Campinas, SP: Mercado das Letras (Col. Ideias sobre Linguagem), 2003.

VAN DIJK, T. A. La ciencia del texto. Barcelona: Ediciones Paidós Ibérica S.A, 1992.

VYGOTSKY, L. S. Pensamento e Linguagem. (Trad: Jeferson Luiz Camargo). São Paulo: Martins Fontes. (Originalmente publicado em 1987), 1991.

VYGOTSKY, L. S. A formação social da mente. Rio de Janeiro: Martins Fontes, 1996.

\section{Endereço para correspondência}

Luciana Ribeiro Pinheiro

Rua Pedro Collere, 168, sobrado 01, Vila Izabel, CEP 80060-140, Curitiba - PR

Rua General Carneiro, 460, Ed. D. Pedro I, 5o Andar, Campus Reitoria, CEP 80060150, Curitiba - PR.

Endereço eletrônico: lucianarp14@yahoo.com.br

Sandra Regina Kirchner Guimarães

Rua Clóvis Bevilaqua, 280, apto 601, CEP: 80.035-080

Rua General Carneiro, 460, Ed. D. Pedro I, 5o Andar, Campus Reitoria, CEP 80060-

150, Curitiba - PR 
Luciana Ribeiro Pinheiro, Sandra Regina Kirchner Guimarães A coerência e a coesão nos textos de opinião de alunos do 5 o ano de ensino fundamental

Endereço eletrônico: srkguimaraes@uol.com.br

Recebido em: 19/03/2012

Reformulado em: 06/02/2012

Aceito para publicação em: 18/03/2013

Acompanhamento do processo editorial: Adriana Benevides Soares

\section{Notas}

* Doutora em Educação pela Universidade Federal do Paraná - Curitiba, Paraná, Brasil.

** Doutora em Psicologia Escolar e do Desenvolvimento Humano pela Universidade de São Paulo

${ }^{1}$ Este artigo é baseado em parte da Tese de doutorado da 1a autora, com o apoio da CAPES, sob orientação da 2 2a autora, apresentada ao programa de pósgraduação em Educação da UFPR. Nossos agradecimentos à Secretaria Municipal de Educação de São José dos Pinhais - PR, à escola e à professora regente da classe investigada, e, especialmente, aos alunos participantes por sua valiosa participação.

${ }^{2}$ Elementos intratextuais são aqueles elementos que fazem parte do texto em si, imprescindíveis para a produção e consequentemente para uma boa compreensão, como: o estilo textual, o tema, o conteúdo, as estruturas textuais internas sejam elas macroestruturais ou microestruturais (coerência e coesão), léxico, estrutura frasal, hierarquia textual, pressuposições, etc.

${ }^{3}$ Circunstâncias intertextuais dizem respeito aos fatores externos ao texto que devem ser consideradas no momento da produção, como: lugar, tempo, cultura do emissor e do receptor, sentido a ser atribuído, motivo da produção, objetivo de comunicação, função textual, etc.

${ }^{4} \mathrm{O}$ nome das duas participantes que aparecem neste artigo são fictícios, eles foram substituídos para preservar a identidade das alunas. 